\title{
Reproduction in young sheep: some genetic and environmental sources of variation
}

\author{
R. B. Land \\ A.R.C. Animal Breeding Research Organisation, West Mains Road, Edinburgh EH9 3JQ, U.K.
}

\begin{abstract}
Summary. 'The extent of genetic and environmental variation' in the development of reproduction in sheep is illustrated by examples with particular reference to variation among breeds and to the effects of photoperiod. The interactions between genetic and environmental effects are introduced; these may be so great that genetic groups may reverse their ranking for rate of development in different environments. The "physiology of puberty' is then discussed. The difficulty of separating puberty from seasonal variation is stressed, and a possible contrast is drawn between the physiological characteristics of genetic variation and those of environmental variation in reproductive development. Finally the physiological factors associated with sterility in young females are discussed; most studies, however, have been conducted during the time of year when adult females would also be expected to be sterile, so that conclusions are difficult and a 'missing link' cannot be identified.
\end{abstract}

\section{Introduction}

Studies of puberty and the early reproductive performance of sheep have recently been comprehensively reviewed by Dyrmundsson (1973a, b). While there is little to add to many of his conclusions, there have been considerable advances in some areas, and these will be emphasized and discussed. It is not proposed to add to the list of definitions of puberty, but simply to regard puberty as embracing the various aspects of the development of reproductive function.

Dyrmundsson concentrated on direct effects rather than interactions. He concluded that the onset of reproductive activity in sheep is affected by genetic and environmental factors-with decreasing daylength and good nutrition speeding the rate of development and vice versa. The effect of photoperiod is well illustrated by his observation "ewe lambs born early in the season tend to attain puberty earlier than those born later, but at a greater age and heavier body weight"; and the effect of nutrition by the observation "faster body growth during rearing will normally favour an earlier onset of first oestrus". Although reproductive development may be affected by genetic and environmental factors, especially nutrition and photoperiod, it is apparent that these effects are not independent, for the magnitude of one effect may be dependent upon the magnitude of the others, and particular attention will be given to interactions of this type (p. 427).

In addition to an increased awareness of the interactions between the various factors affecting reproductive development, the past 4 years have also seen the publication of many data from studies of the endocrine status of the young lamb. Dyrmundsson's observation that "very little seems to be known about the endocrine status of the ewe lamb prior to and during the puberal period" illustrates the speed of recent advances. These will be discussed in relation to genetic and environmental variation on p. 431, and to the causes of sterility of young females (p. 434). It must be remembered throughout that sheep are 'seasonal breeders', in which mating normally takes place in the autumn.

\section{The extent of genetic and environmental variation}

\section{Effects of breed and diet}

Recent studies of breeds of sheep with widely different characteristics illustrate the extent of genetic variation in reproductive development. When kept under similar conditions in the Massif Central, $95 \%$ of Limousin females showed oestrus in the first year of their life, compared to only $26 \%$ of a group of Blanche de Lozere females (Walrave, Cantin, Desvignes \& Thimonier, 1975). This 
effect was not associated with variation in body growth, for the relative body weights of the two groups were similar (60-65\% of adult weight), and, further, there were no differences between the body weights of the Blanche de Lozere females which showed oestrus and those which did not. However, variation in the time of puberty may be associated with variation in body growth, for both are affected by nutrition. This is illustrated by the simple experiment of R. G. Gunn (personal communication); all of 23 Scottish Blackface lambs given supplementary feed showed oestrus in their first breeding season compared to only 15 of 29 lambs not given supplement. The body weights of the two groups were similar at 3 months of age $(21.6$ and $21.5 \mathrm{~kg})$ but differed at 6 months $(33.8$ and $29.8 \mathrm{~kg}$, respectively). The 'environmentally' heavier group (that given supplementary feed) therefore had a higher incidence of oestrus but, as in the experiment of Walrave et al. (1975) in which the main effect was genetic, there was no difference in body weight between those showing oestrus and those not doing so in the group with the lower incidence. Genetic and environmental variation in puberty may therefore be independent of that in body growth.

\section{Genetic variation and the effect of season}

Genetic effects may be considered further in the light of data from the crossing of two breeds with very different characteristics. At one extreme, most Finnish Landrace (Finn) female lambs show oestrus in their first breeding season at about 7 months of age while at the other, very few Tasmanian Merino (Merino) lambs do so, but most Finn $\times$ Merino crossbred lambs do (Land, Russell \& Donald, 1974) (Table 1). The Finn and crossbred females behaved similarly, and matured sexually in their first year, whereas the Merinos did not, despite very similar degrees of maturity of body weight in all three breed types. Exactly the same relationship was observed among males (Table 1), most Finns and crosses mounted oestrous females, gained intromission and ejaculated as lambs, whereas none of the Merinos even mounted the test females, again despite similar degrees of maturity of body weight (Land \& Sales, 1977). Most of the Merino lambs, both male and female, mated when tested in their second 'breeding season'.

Table 1. The sexual and physical maturity of male and female lambs of the Finnish Landrace and Tasmanian Merino breeds and the cross between them at about 7 months of age as measured by the proportion mating and body weight

\begin{tabular}{llcc}
\hline & Finn & Finn $\times$ Merino & Merino \\
\hline No. of females & 36 & 49 & 20 \\
No. showing oestrus (\%) & $35(97)$ & $46(94)$ & $1(5)$ \\
Body weight $(\mathrm{kg})$ & $33 \cdot 5$ & $31 \cdot 9$ & $24 \cdot 5$ \\
$\%$ of weight at 4 years & 55 & 60 & 58 \\
No. of males & 23 & 28 & 9 \\
No. ejaculating (\%) & $21(91)$ & $23(82)$ & $0(0)$ \\
Body weight $(\mathrm{kg})$ & 35 & 36 & 25 \\
$\%$ of weight at 3 years & 54 & 55 & 50 \\
\hline
\end{tabular}

Under these conditions, therefore, the rapid sexual maturity of the Finn is genetically dominant to the slow rate of sexual maturation of the Merino, indicating a contrast between the inheritance of puberty and the additive inheritance of ovulation rate and litter size, but the measurement of puberty is complicated by the seasonality of breeding in the sheep which puts a 'mask' over the age scale. Animals which mature before the onset of the first 'breeding season' of their lives cannot be recognized as mature until the start of the season; likewise, animals which mature soon after the end of the breeding season cannot be recognized until the onset of the next. Females therefore tend to first show oestrus, and males to mount for the first time at about 7 or 19 months of age. The 'mask' effect is illustrated further by the change in testis diameter (Text-fig. 1); in their first season, the testes of Finn and crossbred males grew to approximately $80 \%$ of their second season diameter, whereas the testes of Merino lambs remained at $40 \%$ of their second season diameter until the onset of second season growth. 


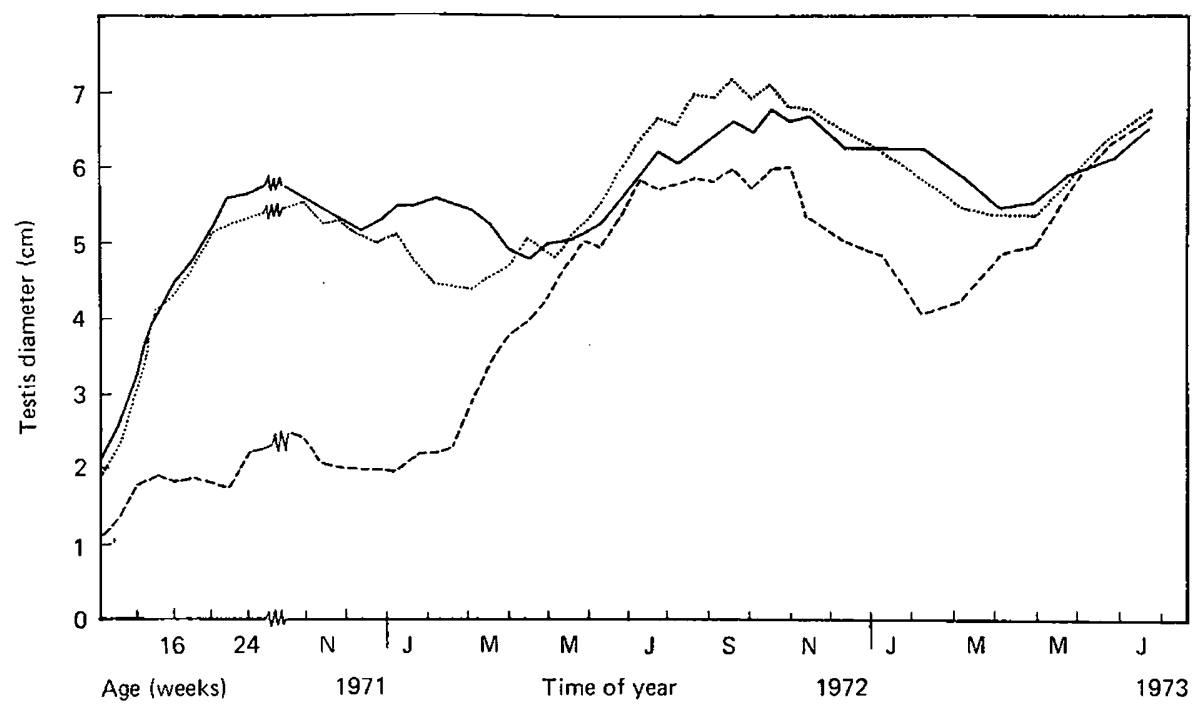

Text-fig. 1. The testis diameter of Finn (-), Merino (---) and crossbred (....) males from May 1971, when 8 weeks of age to July 1973. From Land \& Sales (1977).

The mask analogy, however, although helping the initial appreciation of the problem is an oversimplification. The breeding season is not an all-or-none situation, greater age and a favourable photoperiod both have positive effects on sexual maturation but the magnitude of these effects is under genetic control and, in addition, they may interact. Different individuals or breeds may respond differently to the same change in photoperiod. This is certainly the case for the Finn and Merino breeds studied here. Wheeler \& Land (1977) report that the onset of the breeding season (median date of first oestrus) of Finn ewes is 54 days later than that of Merinos; similarly, the date of smallest testis diameter of Finn rams was found to be 49 days later than that of Merinos (Islam \& Land, 1977). The photoperiodic environmental stimulus to puberty given to a spring-born Merino lamb would therefore be expected to be greater than that given to a spring-born Finn lamb, and one must therefore assume that the failure of the Merino lamb to mature in its first year of life stems from an inability to respond to that stimulus. In the case of the Finn lamb, the stimulus is smaller, but the lamb is able to respond and hence to mature earlier.

The simplest hypothesis to explain this situation is that there are two genetic effects, one which controls the response to a given photoperiodic change, given that an individual is mature enough to respond, and a second, which determines whether it is able to respond. In the Finn and Merino lambs these two underlying traits are acting oppositely on the rate of maturity; the Finn has a 'late' response to the photoperiod, but is able to respond at an early age; the Merino has an early response or would have, but is unable to respond. The simultaneous maturation of the Finn and crossbred lambs could then arise from the additive inheritance of both traits. Photoperiodic effects are, however, confounded with the time of birth, and it is necessary to consider the effects of this component of a lamb's environment before examining the interactions further.

\section{Time of birth}

Testicular growth, as a continuous variable, again serves as a suitable criterion of the effects of time of birth on sexual maturation. Courot, de Reviers \& Pelletier (1975) show that lambs born in autumn (September) mature more rapidly than those born in the spring (February); and the growth of the testes of the two groups is shown in Text-fig. 2. The earlier decline in testis weight in the September-born group may follow an absence of photoperiodic stimulation associated with changes in the duration of the daylength between 155 and 200 days of age or indeed an inhibitory effect of these changes in daylength. In females the absence of photoperiod stimulation at a younger age may 


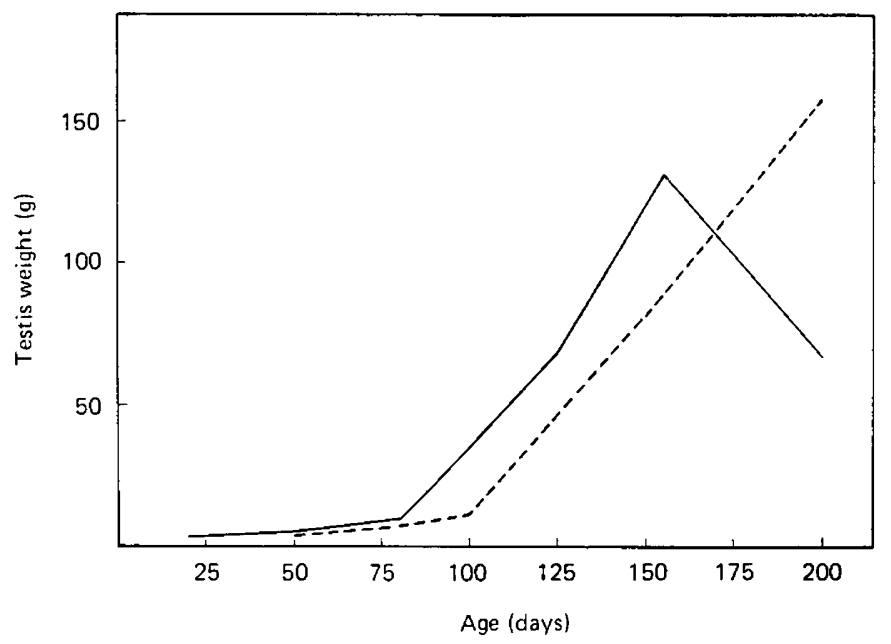

Text-fig. 2. The growth of the testes of Ile-de-France ram lambs born in September (-) or February (---). After Courot, de Reviers \& Pelletier (1975).

lead to autumn-born lambs 'missing' the 'first' breeding season entirely, and showing oestrus at about 1 year of age in the 'second' season of their life. As the time of birth changes from spring to autumn, therefore, puberty would be expected to accelerate, and then suddenly recede as birth becomes too late to allow sexual maturation within the 'first' breeding season.

The effects of season of birth and genotype on sexual maturation are now being studied further at A.B.R.O. Finnish Landrace females are being mated to Finn or Merino rams at different times of the year so that the comparison of pure Finns and Merino $\times$ Finns described earlier can be repeated over different seasons. The long breeding season of the Finn females, extending from October to May (Wheeler \& Land, 1977), makes it ideally suited to this type of study.

Preliminary results with a few animals show that as the date of lambing advanced from early March to mid-April and then to the end of May, the age at first oestrus of Finn females that showed oestrus decreased from 38 to $34 \frac{1}{2}$ to 31 weeks $(\mathrm{F}=4.6$; d.f. 2,$8 ; P<0.05$ ), so that the birth range of 12 weeks was reduced to a range of only 5 weeks in the date of first oestrus $(\mathrm{F}=2 \cdot 3, P>0 \cdot 1)$. In contrast, the range of date of first oestrus of the crossbred lambs showing oestrus was still 10 weeks $(\mathrm{F}=41 \cdot 6$; d.f. 2,$7 ; P<0.001)$, the three groups maturing at 36,33 and 34 weeks of age $(\mathrm{F}=6 \cdot 2$, $P<0.05)$. The response of crossbred females to changes in photoperiod is therefore such that they are able to express their sexual development with little interference from photoperiodic effects even when born as early as the beginning of March. The rate of sexual maturation of Finn females, however, increased markedly as birth became later. The result of this different response to the same photoperiodic changes resulted in the mean age of first oestrus of the early (March) born Finn $\times$ Merino females being 11 days less than that of the early born Finns, whereas in the late (May) born group the situation was reversed, the age of the Merino cross lambs at first oestrus being 22 days greater than that of the comparable Finns.

For the males in this experiment, testis diameter at 24 weeks of age (after correction to a common body weight of $25 \mathrm{~kg}$ ) increased from 5.2 to $5.5 \mathrm{~cm}$ in the purebred Finns as the time of birth advanced from early March to late May, but decreased from 5.6 to $5.0 \mathrm{~cm}$ in the Merino crosses. The photoperiodic stimulus to sexual maturity in the Finn males increased as birth became later, whereas in the Merino crosses it decreased. Although this experiment is still in the early stages, and the results need to be confirmed, the data do indicate that the earlier observation of a similar rate of sexual maturation of Finns and Finn $\times$ Merinos may have been a coincidence of the time of birth; with an earlier or later time of birth, the two breed types differ-a clear example of an interaction between the genotype and the environment. The similarity of the interaction in both sexes, illustrated in Text-fig. 3, supports the hypothesis that the quantitative expression of reproduction is not sex-limited (Land, 1973). 


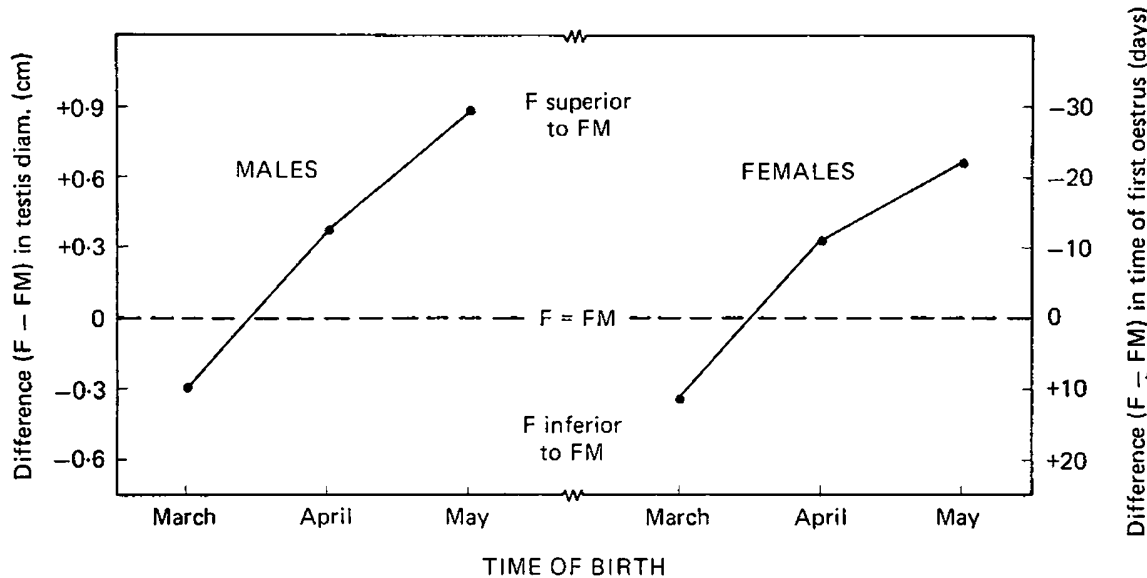

Text-fig. 3. The difference, for males and females, in the sexual maturation of Finnish Landrace (F) and Finnish Landrace $\times$ Tasmanian Merino (FM) lambs as the time of lambing advances from early March to late May, represented by the difference $(F-F M)$ in testis diameter of males at 24 weeks of age, and the date of first oestrus of females.

These experiments indicate that some of the genes controlling sexual development are independent of those involved in the control of the response to seasonal changes in photoperiod. The possibility that the physiological mediation of the action of the genes controlling the response to seasonal changes in the environment may be similar to that of those controlling puberty will be considered later. But first, what are the genetic relationships between male and female maturation within populations of sheep? This problem is being studied at A.B.R.O. by genetic selection for the rate of maturity in one sex, and the examination of correlated changes in the other (Land \& Lee, 1976).

\section{Genetic variation within a population}

Four generations of divergent selection among spring-born Finn-Dorset males for large and small testis diameter at around 10 weeks of age led to a change of 2.6 standard deviations. When the performance of females was examined, by far the most noticeable change was in the onset of the breeding season of adults. The third-generation females of the line selected for large testis size started to show oestrus 3 weeks earlier than those of the line selected for small diameter, even though no artificial selection was applied to any component of female performance at any stage of the selection. It may be concluded that testis growth in sheep of this population and born at this time of the year is partly an expression of genes controlling the response to photoperiod. It may also be affected by genes controlling the intrinsic rate of development, and early and late lambing sublines are being established to assess this.

Both the between- and within-breed studies therefore led to the same conclusion. Variation in the age of puberty of sheep may arise both from variation in the 'response to photoperiod' and from variation in the rate of 'intrinsic development'. As either ceases to be limiting the correlation with the other increases. In early born Finn lambs, puberty is highly correlated with 'response to photoperiod'; as the time of lambing advances this correlation declines and the correlation with 'intrinsic development' increases. In the Finn $\times$ Merino puberty tends to be correlated with the rate of 'intrinsic development' regardless of time of birth, or at least over the times of birth studied above.

\section{Gonadotrophins}

The physiology of puberty

The results of many studies of the concentration of LH in the peripheral plasma of young lambs have been published in recent years together with some of the concentration of FSH; but their interpretation is complicated by the pulsatility of release. Although it may be argued that infrequent blood 
collection samples the population of plasma concentrations, the mean of such a sample does not differentiate between many small pulses and a few large ones; the variance does so but it is a much less powerful discriminator. Mean plasma concentrations must therefore be treated with caution. Furthermore, in the absence of knowledge of hormone catabolism, similar variation in plasma concentrations may not necessarily be associated with similar variation in hormone release. Despite these reservations the data give us many clues about the development of reproductive activity.

Much of our understanding of early sexual development comes from the work of D. L. Foster and his colleagues (see Foster, 1974). The peripheral plasma concentration of LH rises more rapidly in female than in male lambs from birth to 14 days of age, a sex difference which arises from differences in gonadal steroid output rather than hypothalamic or pituitary sensitivity to the negative feed-back effects of these steroids (Foster, Cook \& Nalbandov, 1972). The concentration continues to rise and pass through a maximum but, at least in male lambs, the characteristics of this rise are dependent upon the time of birth relative to the annual change in photoperiod (Courot et al., 1975) and the genotype of the lamb (Blanc, Courot, Pelletier \& Thimonier, 1975). The concentration of LH in peripheral plasma rises more rapidly in ram lambs born in the spring than in ram lambs born in the autumn, and in ram lambs of breeds of high prolificacy than of low prolificacy. The similarity of breeds of high prolificacy and those of spring birth therefore contrast with the more rapid testis growth of autumn born lambs and those of breeds of high prolificacy (discussed above), indicating that the physiological factors underlying seasonal variation in the rate of development of reproductive activity may differ from those underlying genetic variation. It is proposed to discuss the physiological variation associated with seasonal variation and then to compare it with that associated with genetic variation.

\section{Genetic and seasonal variation}

Seasonal variation is difficult to study in females, because physiological differences could be either the cause or the consequence of the presence or absence of cyclicity. Nevertheless, Scaramuzzi \& Baird (1976) and Karsch, Legan \& Ryan (1977) have concluded that seasonal variation arises from an increased sensitivity to negative feed-back from ovarian steroids. In males, however, the comparison is easier, because the nature of their reproductive activity is similar at all times of the year; variation is variation in degree. Pelletier \& Ortavant $(1975 \mathrm{a}, \mathrm{b})$ have shown that seasonal variation in the concentration of $\mathrm{LH}$ in peripheral plasma of males is independent of the presence of the gonads and hence not dependent on variation in negative feed-back from gonadal steroids. The increased sensitivity to testosterone in the season of reduced activity could easily arise from this lower level of basic activity associated with long days. Similarly the reported increased sensitivity of anoestrous females to steroid feed-back could also arise from such a reduction in basic activity.

Seasonal variation, however, is not simply a response to changes in photoperiod, because reproductive status may also change spontaneously. In the studies of Pelletier \& Ortavant (1975a), for example, LH concentration started to rise while daylength was still increasing. This effect is even more marked in the study of Lincoln (1976) in which most of the increase in LH concentration took place before the photoperiod was shortened. Against a steady background of reduced gonadal activity, there appears to be a spontaneous rise in plasma $\mathrm{LH}$, a rise which may be analogous to the prepubertal peak discussed earlier. As daylength continues to shorten (Pelletier \& Ortavant, 1975a) or remains short (Lincoln, 1976) the reverse occurs, gonadal activity increases and the concentration of LH in peripheral plasma declines. Again, this decline is analogous to the prepubertal decline in LH concentration in the lamb. The physiological changes associated with puberty in the male lamb therefore show marked similarities to those associated with seasonal variation in the physiological characteristics of the adult, but this is not surprising, as puberty is associated with the onset of the first breeding season. The use of seasonal variation as a reversible experimental model for puberty in non-seasonal breeders may therefore be unwise; it is also difficult to compare puberty in seasonal breeders with that of animals with no seasonal variation. In the former we have two effects which have not yet been separated, in the latter, puberty alone. The high concentration of peripheral plasma LH before the onset of reproductive activity could be interpreted to indicate that puberty in sheep is not 
dependent upon a decreased sensitivity of the hypothalamus to the negative feed-back of gonadal steroids, but it could be an effect of season, the greater the correlation between age of puberty and 'response to photoperiod', the greater the prepubertal LH peak.

To study the differences between puberty and the onset of the breeding season, it may be necessary to study animals in a stimulatory photoperiod, but the characteristics of a stimulatory photoperiod may be different for each individual or each breed. It must also be remembered that in studies in which single samples are taken, similar mean plasma concentrations may hide differences in pulse size or frequency. Puberty and seasonal variation could both be associated with changes in pulse frequency rather than rates of synthesis and total release; although Foster (1974) shows an increase in pulse size and frequency with age, he does not discuss the age of his juveniles relative to the stage of the season. To add to these complications it must also be remembered that there is a considerable body of evidence to suggest that the reproductive status of sheep is unstable. We have seen that males in a constant photoperiod tend to alternate between reproductive activity and inactivity. Sheep may ovulate during anoestrus, and oestrous cycles may resume before the daylength has shortened (Thimonier \& Mauléon, 1969); the maintenance of a short photoperiod from the shortest day onwards does not affect the duration of the breeding season (Speedy \& Owen, 1975). With such instability, which itself may be subject to genetic variation, and the superimposition of the effects of changes in daylength, it is hardly surprising that although much is now known about the endocrinological events associated with puberty they are not yet fully understood. Let us return to the question of genetic variation.

\section{Relationships between prepubertal endocrinology and adult performance}

The most marked genetic differences in the concentration of $\mathrm{LH}$ in the peripheral plasma of immature lambs is reported by Blanc et al. (1975) for different breeds; the rate of increase in LH concentration in the plasma of lambs of the highly prolific Romanov breed was much greater than that for Ile-de-France or Prèalpe lambs. It may be argued that the rapid rise in plasma $\mathbf{L H}$ and high rates of testicular growth may arise from a lower sensitivity of the highly prolific breeds to negative feed-back from gonadal steroids, and this is supported by the observation that hemicastration leads to greater increases in the rate of growth of the remaining testis of ram lambs of breeds of low prolificacy than of high prolificacy (Land \& Carr, 1975). Several workers, however, have reported no association between the concentration of $\mathrm{LH}$ in peripheral plasma of young rams and the prolificacy of the breed type, and the incompatability of these results is discussed by Land \& Carr (1978). They point out that with an age-dependent prepubertal peak LH concentration, the relative ranking of different breeds is dependent upon the age at the maximum concentration for each breed and the age at which the comparison is made. The model proposed is illustrated in Text-fig. 4. At a very early age all breeds would have similar LH concentrations. As they became older, the lambs of the highly prolific breed would have higher concentrations of I.H in peripheral plasma than would lambs of the lowly prolific breed, but once the lambs of the highly prolific type pass their maximum, the two types would first be similar, and then reverse rankings as the concentration continued to increase in the lambs of the type with low prolificacy. Again, the importance of season must not be neglected. We have seen that early born Finn-Merino lambs mature more or as rapidly as Finns, but when born later, the situation is reversed; the age of maximum LH concentration may also reverse. Not only is the ranking of breed types affected by the age of observation, this may also interact with the time of birth. The study of the physiology of genetic and environmental variation in puberty of the sheep is therefore only just beginning. We have sufficient data to show that the genetic and environmental sources of variation may interact, and to show that the separation of these effects and the understanding of their physiological mediation will be dependent upon thorough investigation.

Variation in the physiology of the immature lamb is of interest both in its own right but also with a view to the possibility that an understanding of the variation may lead to the development of criteria to predict adult performance. More especially, the possibility that a ram's juvenile characteristics may be used to predict the reproductive performance of his daughters would be of particular value (Land, 1973). Such a predictive estimate could be used as a criterion for selection for female traits, 


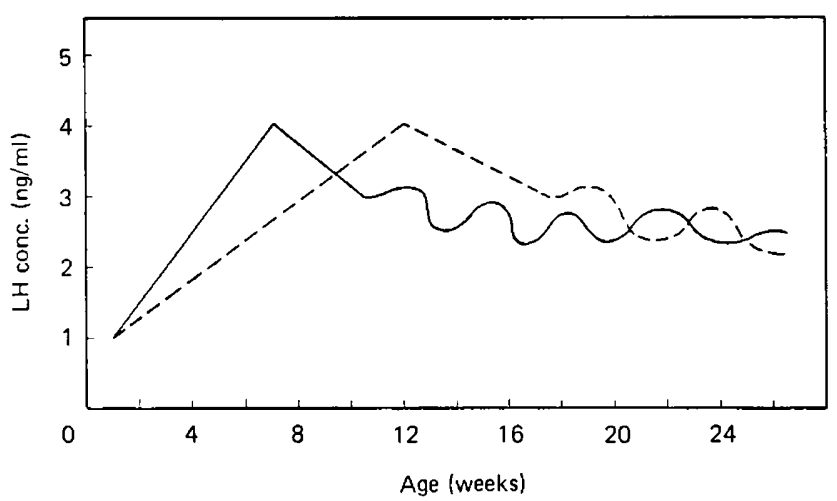

Text-fig. 4. The change in peripheral plasma LH concentration of lambs of high (-) and low (---) prolificacy breed types with time. After Land \& Carr (1978).

and could have a large effect on the rate of genetic change. One possible criterion is testis growth, and the effect of selection for testis growth on seasonal variation in female performance has already been discussed. While it is possible that selection for testis growth in a stimulatory photoperiod would lead to changes in litter size it is not necessarily convenient or always possible to lamb ewes in the summer or to change the photoperiod artificially during rearing. An alternative approach to the problem has been to use the response to LH-RH (Carr, Land \& Sales, 1976). This and further studies (Land \& Carr, 1978) show that differences in the prolificacy of the breed type are associated with differences in the response to LH-RH. Furthermore, the differences are recognizable in spring-born lambs and this gives an 'LH-RH test' a possible advantage over testis growth, which, as discussed above, may be similar in the males although Finn and Finn-Merino females have very different litter sizes. Again, however, the problems of breed $\times$ season $\times$ age interactions have to be considered. Galloway \& Pelletier (1974) showed that the characteristics of the response to LH-RH change with age, but they do not separate the effects of age from those of season; furthermore, by giving a dose according to body weight they may have introduced an extra variable. In an attempt to separate these interactions, the response to LH-RH is being studied in the Finn-Merino crossing experiment described earlier, because the same breeds can be studied at different ages in the same season and at the same age in different seasons.

\section{The missing link?}

The ovary of the new-born lamb contains many oocytes and follicles, some of which have antra, and their development in the Merino lamb is described by Kennedy, Worthington \& Cole (1974). As with other reproductive characteristics of the immature animal, this development is under quantitative genetic control, lambs of highly prolific breed types have a smaller total number of oocytes but a greater proportion of follicles with antra (Land, 1970). The follicles are able to respond to exogenous gonadotrophins and ovulation may be induced (Mansour, 1959). If intrauterine insemination is used to bypass the cervical block, the eggs ovulated may be fertilized (Land \& McGovern, 1968), and when transferred to adults at an appropriate stage of the oestrous cycle they develop normally (Trounson, Willadsen \& Moor, 1977). The latter authors also demonstrated that the capacity of the lamb follicle to secrete oestrogen, testosterone and progesterone in vitro was similar to that of the adult. The oestrogen-preovulatory LH discharge reflex is competent at 5-6 weeks of age (Land, Thimonier \& Pelletier, 1970). The concentration of LH in peripheral plasma is within the range of that of the adult (Foster, 1974), but closer to that of the castrated than the intact ewe. Similarly, Foster (1974) concludes that the concentration of FSH in the peripheral plasma of the immature is similar to that of the adult sheep. All links in the chain to ovulation are therefore competent when tested separately and immaturity has tended to be considered a question of integration, a question of the quantitative relationships between the links, rather than of their qualitative presence. Such a conclusion, however, 
is an admission of ignorance rather than the positive description of a cause. Moreover the study of adult, 'mature' females at the same time of year as that at which most of the lamb studies have been conducted would have led to essentially the same conclusion. With lambs tending to be born at the start of the anoestrous season, most studies have taken place when adults are anoestrous. Sexual immaturity cannot be compared to seasonal dysfunction until the two are separated.

It may be argued in general that sterility is of selective advantage to the physically immature individual, for conception at too small a proportion of adult body weight may lead to reduced viability of both dam and conceptus. As such, we have to admit that we do not know how conception is prevented. Such knowledge may be relevant to the study of human contraception, but it may be simpler to study the problem in an experimental animal whose reproductive activity is less sensitive to environmental variation than is that of the sheep.

\section{References}

Blanc, M.R., Courot, M., Pelletier, J. \& Thimonier, J. (1975) Etude de la puberte et de la saison sexuelle chez les races proliviques et leurs croisements avec des races francaises. In Les Races Prolifiques, pp. 18-37, INRA/ITOVIC, Paris.

Carr, W.R., LAND, R.B. \& SALES, D.I. (1976) The effect of gonadotrophin releasing hormone $(\mathrm{GnRH})$ on plasma levels of luteinizing hormone ( $\mathrm{LH})$ in lambs of breeds with high and low ovulation rates. Annls Biol. anim. Biochim Biophys. 16, 167, Abstr.

Courot, M., de Reviers, M.M. \& Pelletier, J. (1975) Variation in pituitary and blood LH during puberty in the male lamb. Relation to time of birth. Annls Biol. anim. Biochim. Biophys. 15, 509-516.

DYRMundsson, O.R.(1973a) Puberty and early reproductive performance in sheep. 1. Ewe lambs. Anim. Breed. Abst. 41, 273-289.

DRYMUNdsson, O.R. (1973b) Puberty and early reproductive performance in sheep. II. Ram lambs. Anim. Breed. Abstr. 41, 419-430.

Foster, D.L. (1974) Regulation of gonadotrophins during fetal development in the sheep. In Sexual Endocrinology of the Perinatal Period, Vol. 32, pp. 143-156. INSERM, Paris.

Foster, D.L., Cook, B. \& Nalbandov, A.V. (1972) Regulation of luteinizing hormone (LH) release in the fetal and neonatal lamb: effect of castration during the early post-natal period on levels of $\mathrm{LH}$ in sera and pituitaries of neonatal lambs. Biol. Reprod. 6, 253-257.

Galloway, D.G. \& Pelletier, J. (1974) Influence of age on the pituitary response of male lambs to synthetic LH-RH injection. Horm. Metab. Res. 6, 240-241.

IsLAM, A.B.M.M. \& LAND, R.B. (1977) Seasonal variation in testis diameter and sperm output of rams of breeds of differing prolificacy. Anim. Prod. (In press).

KarsCH, F.J., Legan, S.J. \& RYAN, K.D. (1977) The feedback effects of ovarian steroids on gonadotrophin release. In Control of Ovulation. Butterworth, London.

Kennedy, J.P., Worthington, C.A. \& Cole, E.R. (1974) The post-natal development of the ovary and uterus of the Merino lamb. J. Reprod. Fert. 36, 275-282.
LAND, R.B. (1970) Number of oocytes present at birth in the ovaries of pure and Finnish Landrace cross Blackface and Welsh sheep. J. Reprod. Fert. 21, 517521.

LAND, R.B. (1973) The expression of female sex-limited characters in the male. Nature, Lond. 241, 208-209.

LAND, R.B. \& CARR, W.R. (1975) Testis growth and plasma LH concentration following hemicastration and its relation with female prolificacy in sheep. J. Reprod. Fert. 45, 495-501.

LAND, R.B. \& CARR, W.R. (1978) Reproduction in domestic mammals. In Genetic Variation in Hormone Systems. Ed. J. G. M. Shire. C.R.C. Press, Cleveland.

LAND, R.B. \& LeE, G.J. (1976) Testis growth, a possible genetic predictor of female reproductivity. Anim. Prod. 22, 137 Abstr.

LAND, R.B. \& MCGOVERN, P.T. (1968) Ovulation and fertilization in the lamb. J. Reprod. Fert. 15, 325-327.

LAND, R.B. \& SALES, D.I. (1977) Mating behaviour and testis growth of Finnish Landrace, Tasmanian Merino and crossbred rams. Anim. Prod. 24, 89-90.

Land, R.B., Thimonier, J. \& Pelletier, J. (1970) Possibilité d'induction d'une decharge de LH par une injection d'oestrogen chez l'agneau femelle en fonction de l'âge. C. r. hebd. Séanc. Acad. Sci., Paris 271, 1549-1551.

LAND, R.B., Russell, W.S. \& Donald, H.P. (1974) The litter size and fertility of Finnish Landrace and Tasmanian Merino sheep and their reciprocal crosses. Anim. Prod. 18, 265-271.

LINCOLN, G.A. (1976) Seasonal variation in the episodic secretion of luteinizing hormone and testosterone in the ram. $J$. Endocr. 69, 213-226.

MANSOUR, A.M. (1959) The hormonal control of ovulation in the immature lamb. J. agric. Sci., Camb. 52, 87-93.

Pelletier, J. \& Ortavant, R. (1975a) Photoperiodic control of $\mathrm{LH}$ release in the ram. I. Influence of increasing and decreasing photoperiods. Acta endocr., Copenh. 78, 435-441.

Pelletier, J. \& Ortavant, R. (1975b) Photoperiodic control of LH release in the ram. II. Light-androgens interaction. Acta endocr., Copenh. 78, 442-450.

SCARAmUZzI, R.J. \& BaIRD, D.T. (1976) Ovarian steroid secretion in sheep during anoestrus. Sheep Breeding, 
pp. 330-337. Eds G. J. Thomas, D. E. Robertson \& R. J. Lightfoot. W. Aust. Inst. Tech.

SPEEDY, A.W. \& OWEN, J.B. (1975) Factors affecting the cessation of oestrus activity in ewes. Anim. Prod. 21, 251-255.

Thmonier, J. \& Mauléon, P. (1969) Variations saisonnières du compartement d'oestrus et des activités ovarienne et hypophysaire chez les ovins. Annls Biol. anim. Biochim. Biophys. 9, 233-250.

Trounson, A.O., Willadsen, S.M. \& Moor, R.M. (1977) Reproductive function in prepubertal lambs: ovulation, embryo development and ovarian steroidogenesis. J. Reprod. Fert. 49, 69-75.

Walrave, W., Cantin, P., Desvignes, A. \& Thimonier, J. (1975) Variations saisonnières de l'activité sexuelle des races ovines du Massif Central. In Les Races Prolifique, pp. 261-271. I.N.R.A.I.T.O.V.I.C., Paris.

Wheeler, A.G. \& LAND, R.B. (1977) Seasonal variation in oestrus and ovarian activity of Finnish Landrace, Scottish Blackface and Tasmanian Merino ewes. Anim. Prod. 24, 363-376. 